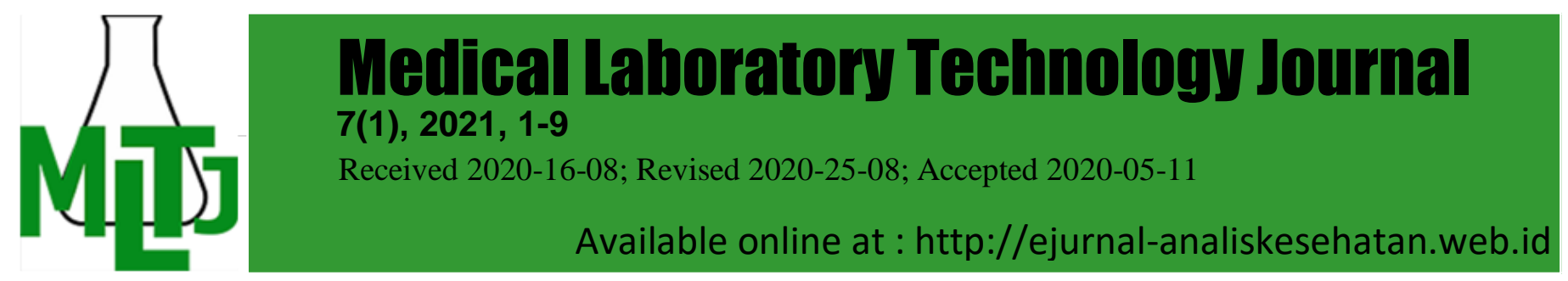

\title{
Effect of Propolis on the Adhesion Index, Morphology and Viability of Candida albicans Cells on Biofilm Formation
}

\section{Dinda Oktia Maghfiroh ${ }^{1}$, A.A. Santi Dewi ${ }^{1}$, Anggie Diniayuningrum ${ }^{1}$, Bambang Rahardjo², Nurdiana ${ }^{3}$, Agustina Tri Endharti ${ }^{4}$, ${ }^{\text {Sumarno }}{ }^{5}$}

\author{
${ }^{1}$ Master of Midwifery, Faculty of Medicine, Brawijaya University, Indonesia, \\ ${ }^{2}$ Department of Obstetric and Gynecology, Faculty of Medicine, Brawijaya University, \\ Saiful Anwar General Hospital, Indonesia, ${ }^{3}$ Department of Pharmacology, Faculty of \\ Medicine, Brawijaya University, Indonesia, ${ }^{4}$ Department of Parasitology, Faculty of \\ Medicine, Brawijaya University, Indonesia, ${ }^{5}$ Department of Microbiology, Faculty of \\ Medicine, Brawijaya University, Indonesia. \\ *Email: sumarno.fk@ub.ac.id \\ DOI: 10.31964/mltj.v0i0.322
}

\begin{abstract}
About $70-75 \%$ of reproductive women have experienced vulvovaginal candidiasis at least once and $40-45 \%$ will have recurrences. Candida albicans is the most etiology of vulvovaginal candidiasis and is able to form biofilm that can lead to antifungal resistances and recurrences. One of the natural products that have an antibiofilm effect is propolis. This study expected that propolis from Lawang can be the one of antibiofilm agent candidates to antifungi resistant cases. This study aimed to know the antibiofilm effect of propolis ethanol extract to cell adhesion index, morphology, and viability of Candida albicans cell on biofilm formation. The adhesion index was counted on 100 epithelial cells under light microscopy (1000x). Morphology was seen using light microscopy (400x). Cell viability was examined by CFU assay. At $12.5 \%$ concentration of propolis ethanol extract, adhesion index decreased $(p=0,000)$ and hyphal growth was inhibited. Colony growth decreased at $2.5 \%$ concentration and was not seen at $10 \%$ concentration of propolis ethanol extract $(p=0,000)$. This results indicated that propolis ethanol extract can decrease adhesion index, failed the Candida albicans morphology transition from yeast to hyphal, and decreased Candida albicans cell viability on biofilm formation. Propolis ethanol extract is likely to be one of alternatives to recurrent vulvovaginal candidiasis treatment, especially caused by Candida albicans biofilm formation.
\end{abstract}

Keyword: Propolis; adhesion index; morphology; cell viability; Candida albicans

\section{INTRODUCTION}

Vulvovaginal candidiasis is a disease that attacks the vulva and/or intravaginal (Gonçalves et al., 2016). Vulvovaginal candidiasis affects $70-75 \%$ of women's reproductive. About $40-45 \%$ of them experience vulvovaginal candidiasis for the second time. Recurrent infections (four episodes or more) can occur in about $5-8 \%$ of women (Sobel, 2016). Candida albicans (C. albicans) is the most common cause of vulvovaginal candidiasis with a percentage of $70-89 \%$ (Gonçalves et al., 2016). One of the virulence forms of $C$. albicans is biofilm formation. Biofilm is a community of microorganism cells that attach to a surface and encase in an extracellular matrix produced by the microorganisms themselves (Rodríguez-Cerdeira et al., 2018).

Biofilm formation occurs in 4 stages, namely cell adhesion, initiation, maturation, and dispersion (Ranjith et al., 2018). Adhesion of $C$. albicans cells to host cells is a 
prerequisite for biofilm formation (Dwivedi et al., 2019). Adhesion is a complex process resulting from the simultaneous interaction between fungal cell wall components and biomolecules on the surface of the host cell membrane (Nikou et al., 2019). McCall et al. (2019) showed that the adhesion of wild type $C$. albicans cells increased during growth along with the increase of Hyphall formation. Hyphal morphogenesis plays an important role in adhesion to biofilm development. The morphological transition from yeast to Hyphal or filaments are markers of invasion and the essence of pathogenesis, thereby increasing the ability of $C$. albicans to form biofilms (Cavalheiro and Teixeira, 2018). In the formation of $C$. albicans biofilm, Hyphal plays a role in providing structural stabilization, moreover, it keeps the yeast and cellular matrix in the maturation phase (Mutiawati, 2016). The formation of mature biofilm can increase cell viability and resistance to anti-fungal agents and antibiofilm (Lohse et al., 2018).

One of the alternative therapies from the natural product is propolis. Propolis is a natural product produced by honey bees (Capoci et al., 2015). Study conducted by de Castro et al. (2013) showed that Brazilian propolis inhibit C. albicans biofilm formation in vulvovaginal candidiasis; induces cell apoptosis (de Castro et al., 2013); and degrades the Extracellular Polymeric Substance (EPS). One of the compounds in propolis that has been known to act as an antibiofilm is a flavonoid (Przybylek and Karpinski, 2019). But, the composition of propolis can vary depending on the type of plant where the bees live (Silva-Carvalho et al., 2015), time of collection, and geographical origin (Anjum et al., 2018). Propolis used in this study was from Lawang, Malang, Indonesia. Hadi et al. (2019) showed that ethanolic extract of Propolis Trigona sp from Lawang Indonesia inhibited the production of Staphylococcus aureus biofilm but not known the antibiofilm effect of Propolis from Lawang, Indonesia to fungi, especially $C$. albicans. The purpose of this study was to know the effect of propolis ethanol extracts on the cell adhesion index, morphology, and viability of $C$. albicans cells on biofilm formation.

\section{MATERIALS AND METHOD Propolis Ethanol Extract}

Propolis used in this experiment was honey bee production by Trigona sp. species which comes from Rimba Raya Wasp Farm, Lawang, Malang, Indonesia. Propolis was extracted by maceration method with $70 \%$ ethanol solvent. The concentrations of Propolis ethanol extract (PEE) include 2.5\%; 5\%; 7.5\%; $10 \%$; and $12.5 \%$. Approval for this study was obtained from Ethics Comission of Medical Faculty, Brawijaya University No.88/EC/KEPK-S2/04/2020.

\section{C. albicans cultures}

C. albicans isolates were obtained from the Microbiology Laboratory, Faculty of Medicine, Brawijaya University, Malang, Indonesia. C. albicans cells were cultured in SDA (Oxoid) medium at $37^{\circ} \mathrm{C}$ for $24 \mathrm{~h}$. The results of the incubation were harvested for biofilm formation.

\section{C. albicans Biofilm Formation}

C. albicans suspension was adjusted to $10^{7} \mathrm{CFU} / \mathrm{mL}$. Then, the cells were added to 96-well flat-bottom plates (Costar Corning) that contain SDB medium (MERCK)+Glucose 2\% (MERCK) and some concentrations of PEE. Then, the plate was incubated at $37^{\circ} \mathrm{C}$ for $48 \mathrm{~h}$ (Gulati et al., 2018). This assay was performed in four replications.

\section{Adhesion Index}

Adhesion index measurement was performed on vaginal epithelial cells of Rattus norvegicus Wistar strain. Epithelial cell isolation was performed according to 
the Weisser method (Nagayama et al., 1995). Adhesion test used the method according to El-Din et al. (2012) with a modification of $0.5 \mathrm{~mL}$ of epithelial cells $\left(10^{5}\right)$ and $0.5 \mathrm{~mL}$ of $C$. albicans cells $\left(10^{7}\right)$ homogenized, added PEE, and incubated for 60 minutes on shaking water bath (Medlab Solution) at a temperature of $37^{\circ} \mathrm{C}$. Then 10 $\mu \mathrm{L}$ of the suspension was dropped on object-glass, fixed, and Gram stained. This assay was performed in four replications.

$$
\text { Adhesion Index }=\frac{\text { Total of C.albicans on epithelial cells } 1-100}{100}
$$

\section{Morphology of C. albicans (Hyphal Growth)}

C. albicans cell suspension $\left(1 \times 10^{6} \mathrm{CFU} / \mathrm{mL}\right)$ was prepared in RPMI- 1640 (Gibco) containing 10\% Fetal Bovine Serum (FBS) (Sigma) and some concentrations of PEE. The sample was incubated at $37^{\circ} \mathrm{C}$ for $6 \mathrm{~h}$. This assay was performed in four replications. The cell morphology was monitored by photographed (Olympus $\mathrm{CH} 2$, Olympus, Tokyo, Japan) at 400x magnification.

\section{C. albicans Cell Viability}

C. albicans cell viability on biofilm formation was performed by counting the colony growth. Briefly, the same procedure was performed as biofilm formation. After biofilm was formed, the suspension was diluted $1000 \mathrm{x}$. Then, $10 \mu \mathrm{L}$ suspension was streaked in the SDA medium (Oxoid) at $37^{\circ} \mathrm{C}$ for $24 \mathrm{~h}$. This assay was performed in four replications. Colony growth was counted using a colony counter (Funke Gerber) (Capoci et al., 2015).

\section{Statistical Analysis}

Data of the results was performed in Mean \pm SD. Results were analyzed using one-way ANOVA with the Bonferroni test and Tukey Post-Hoc (SPSS version 23). Values of $p \leq 0.05$ were considered significant statistically.

\section{RESULTS AND DISCUSSION \\ Propolis Ethanol Extract and C. albicans adhesion index to Rattus norvegicus vaginal epithelial cells}

Adhesion assay was performed to determine the effect of propolis ethanol extract on the adhesion index of $C$. albicans to vaginal epithelial cells of Rattus norvegicus. The result showed that adhesion index decreased with the increase of propolis ethanol extract (PEE) concentration (Fig 1). The lowest average of the adhesion index was at the concentration of $12.5 \%$ propolis ethanol extract. At a concentration of $12.5 \%$ propolis ethanol extract, $C$. albicans attached to one vaginal epithelial cell of Rattus norvegicus is $3.37 \pm 0.252$ ( 3 cells of $C$. albicans). The highest average of the adhesion index was at the concentration of $2.5 \%$ propolis ethanol extract. At a concentration of $12.5 \%$ propolis ethanol extract, C. albicans attached to one vaginal epithelial cell of Rattus norvegicus is $10.12 \pm 0.398$ (10 cells of C. albicans). The analysis of the one-way ANOVA test showed a significant difference in the control and the treatment group $(p$-value $=0.000)$. The post-Hoc-Tukey test showed that the adhesion index on all treatment groups significantly decreased compared with the control. It is demonstrated that the increase of propolis ethanol extract concentration is associated with the decrease of $C$. albicans adhesion index to Rattus norvegicus vaginal epithelial cells. The results of the research have demonstrated the concentration of $12.5 \%$ propolis ethanol extract is an effective dose to reduce the adhesion index of $C$. albicans. 


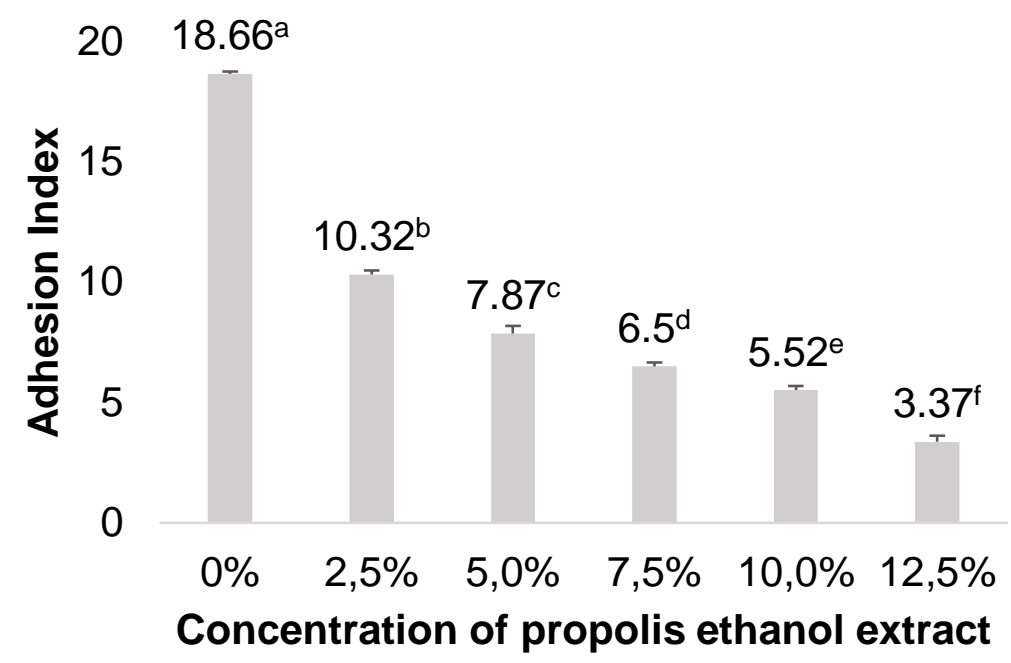

Figure 1. The Average of $C$. albicans Adhesion Index to Rattus norvegicus Vaginal Epithelial Cells after Treatment with PEE. The Histogram Showed that PEE Reduces the $C$. albicans Adhesion Index to Rattus norvegicus Vaginal Epithelial Cells.

Previous research reported the same result about PEE effect to adhesion of C. albicans. The study conducted by Nani et al. (2019) reported that $100 \mu \mathrm{g} / \mathrm{ml}$ of Brazilian Organic Propolis can reduced the adhesion of $C$. albicans to human keratynocytes. The percentage of $C$. albicans adhering to human keratinocyte cells after being treated with Brazilian Organic Propolis is approximately $30 \%$. In our study, the adhered cells percentage is $18.06 \%$ at a concentration of $12.5 \%$. This indicate that our propolis is probably has more flavonoid content. Adhesion inhibition can prevent fungi to interact with host cells and inhibit biofilm formation (Zhang et al., 2016). One of the main bioactive components contained in propolis is a flavonoid (Silva-Carvalho et al., 2015). Flavonoid can interfere with the formation of $C$. albicans cell wall by inhibiting the synthesis of $\beta$-glucan and chitin, which is the main component of the cell wall (Aboody et al., 2020). Antifungal agents will invade cells, such as through active transport, and interfere with the RNA synthesis. Therefore, it can cause RNA synthesis error, inhibit DNA transcription, and inhibit the protein synthesis process (Lagrough et al., 2017). Morphological changes also affect adhesion ability, such as $C$. albicans hyphal has stronger adhesion ability than the yeast form (Richardson et al., 2018). Okinczyc et al. (2020) reported that Nepal propolis can inhibit hyhal formation and decrease the virulence of $C$. albicans due to changes in cell hydrophobicity. Changes in cell surface hydrophobicity will affect the ability of $C$. albicans to adhere to epithelial cells (Richardson et al., 2018).

\section{Propolis Ethanol Extract inhibit C. albicans Morphology}

We evaluated propolis ethanol extract (PEE) to failure transition from yeastlike to hyphal growth in $C$. albicans culture (Fig 2). C. albicans cultures that were not treated with PEE showed that yeast cells were able to form and produce elongated and regular hyphal cells. At $7.5 \%$ concentration of PEE, yeast cells had inhibition of pseudohyphae formation. Treatment of PEE with a concentration of $12.5 \%$ showed yeast cells decrease. This indicates that yeast cells can not produce asexually and are unable to form blastospore (budding). 


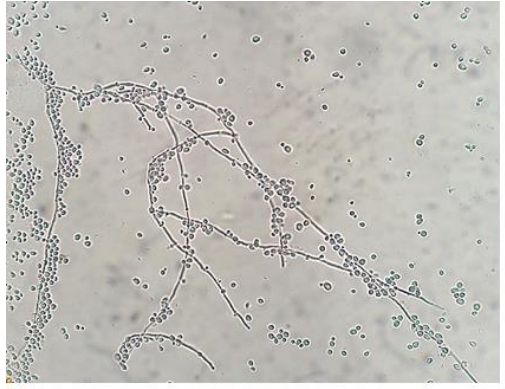

Control

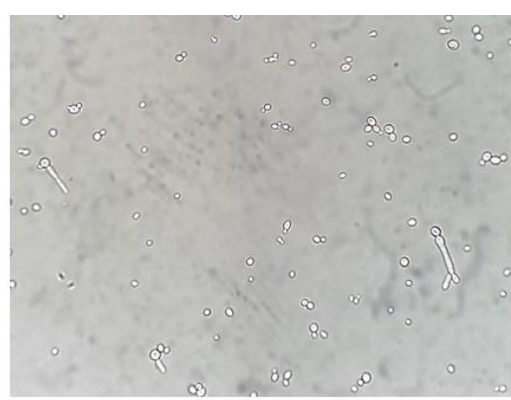

PEE $7,5 \%$

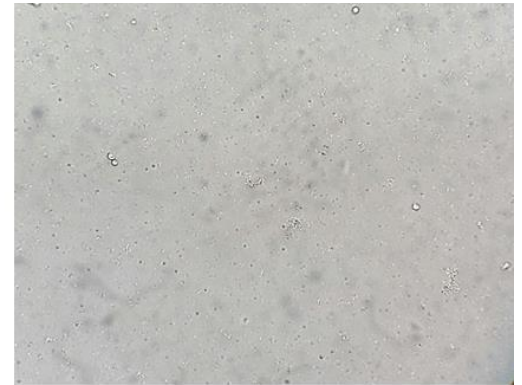

PEE $12,5 \%$

Figure 2. Effect of Propolis Ethanol Extract Inhibits on C. albicans Morphology. $C$. albicans Cells were Grown in RPMI-1640 Medium Containing 10\% Fetal Bovine Serum (FBS) at Some Concentrations of Propolis at $37^{\circ} \mathrm{C}$ for $6 \mathrm{~h}$. Samples were Withdrawn after Incubation and Photographed at 400x Magnification.

The ability of $C$. albicans to transition from yeast-like to hyphal growth will increase its virulence compared to the form of planktonic/yeast cells because hyphal has a larger size than spores which will complicate the phagocytosis process by macrophages (Li et al., 2019). The hyphal formation which has intensive ability to tissue invasion and infiltration plays an important role in the pathogenesis (Valerio et al, 2016). The experiment conducted by Valerio et al. (2016) has a similiar result with our study. They revealed that Green Brazilian propolis extract can inhibit the formation of hyphal at $450 \mu \mathrm{g} / \mathrm{ml}$ propolis extract (PE). At this concentration, PE was able to block $90 \%$ of transition from yeast-hyphal growth in $C$. albicans. Therefore, our study showed that hyphal growth did not seen at $7.5 \%$ concentration of PEE from Lawang, Malang, Indonesia. According to Chua et al. (2014), a flavonoid contained in propolis interacts with cellular sulfhydryl compounds on the cell wall, which causes detachment of the yeast cell wall and reduction of germ tube formation and hyphal length. As a result, it inhibits the yeast-mycelium transition which ultimately prevents cell division.

\section{Propolis Ethanol Extract Can Decrease C. albicans Cell Viability on Biofilm Formation}

C. albicans cell viability test was performed using a colony-forming unit (CFU) assay. The result showed that colony growth decreased with the increased of propolis ethanol extract (PEE) concentration (Fig 3). Colony growth started to decline at $2.5 \%$ of PEE (1069101 CFU/mL). Then, colony growth at $5 \%$ of PEE was $459402 \mathrm{CFU} / \mathrm{mL}$ and $13750 \mathrm{CFU} / \mathrm{mL}$ at $7.5 \%$ of PEE. Colony growth did not seen at $10 \%$ and $12.5 \%$ concentration of PEE (0 CFU/mL) (Fig 4). Therefore, $10 \%$ concentration of PEE had been able to inhibit $C$. albicans cell growth. It is indicated that PEE can decrease $C$. albicans cell viability on biofilm formation. Moreover, the result of the One-Way ANOVA statistic test showed a significant difference between colony growth on each concentration $(p=0,000)$. 


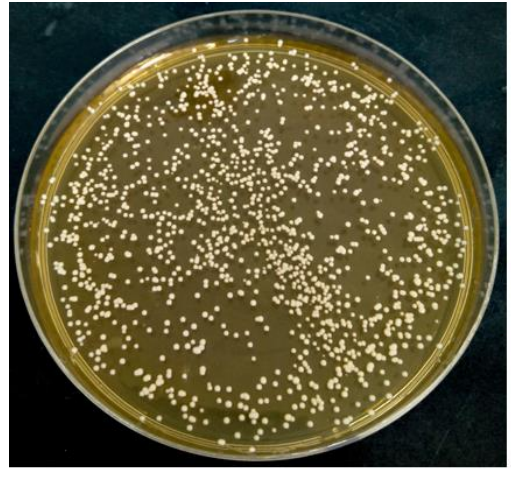

PEE 0\% (Control)

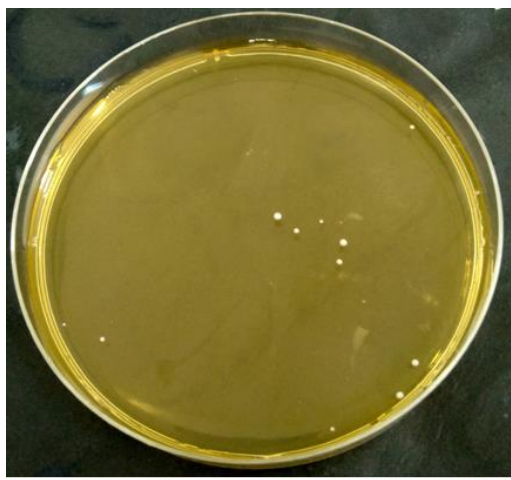

PEE $7,5 \%$

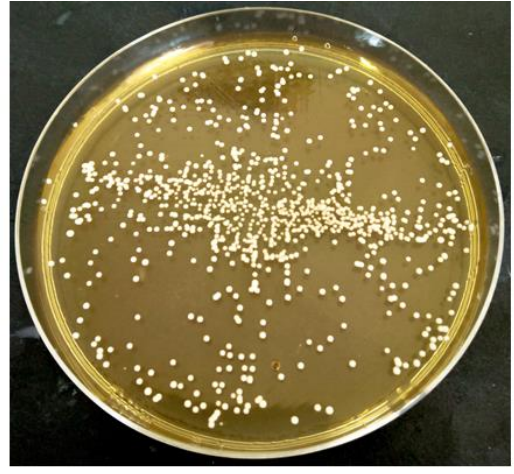

PEE $2,5 \%$

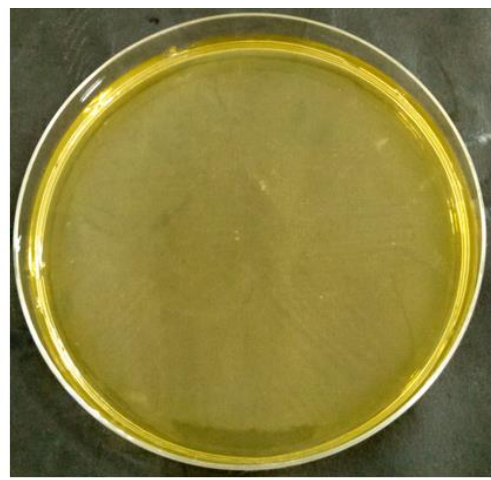

PEE $10 \%$

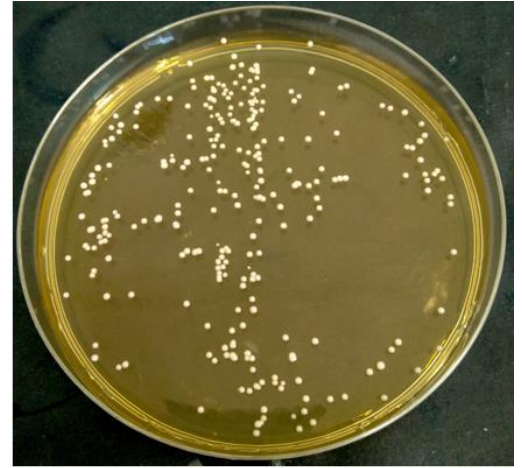

PEE 5\%

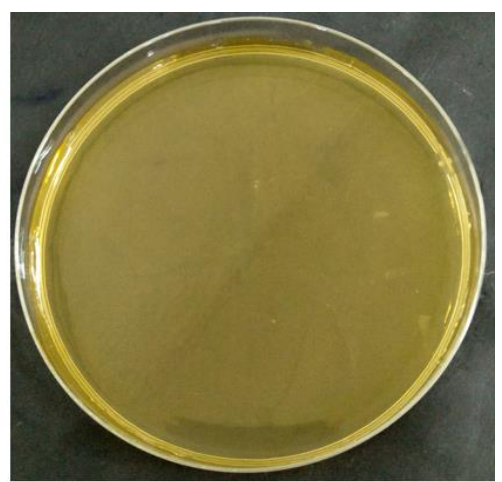

PEE $12,5 \%$

Figure 3. C. albicans Colony Growth in SDA Medium on Biofilm Formation with some Concentrations of Propolis Ethanol Extract Treatment (0\%; 2.5\%; 5\%; 7.5\%; 10\%; $12.5 \%)$. Colony was Counted Using Colony Counter. This Showed that Colony Growth Decreased with the Increased of Propolis Ethanol Extract Concentration.

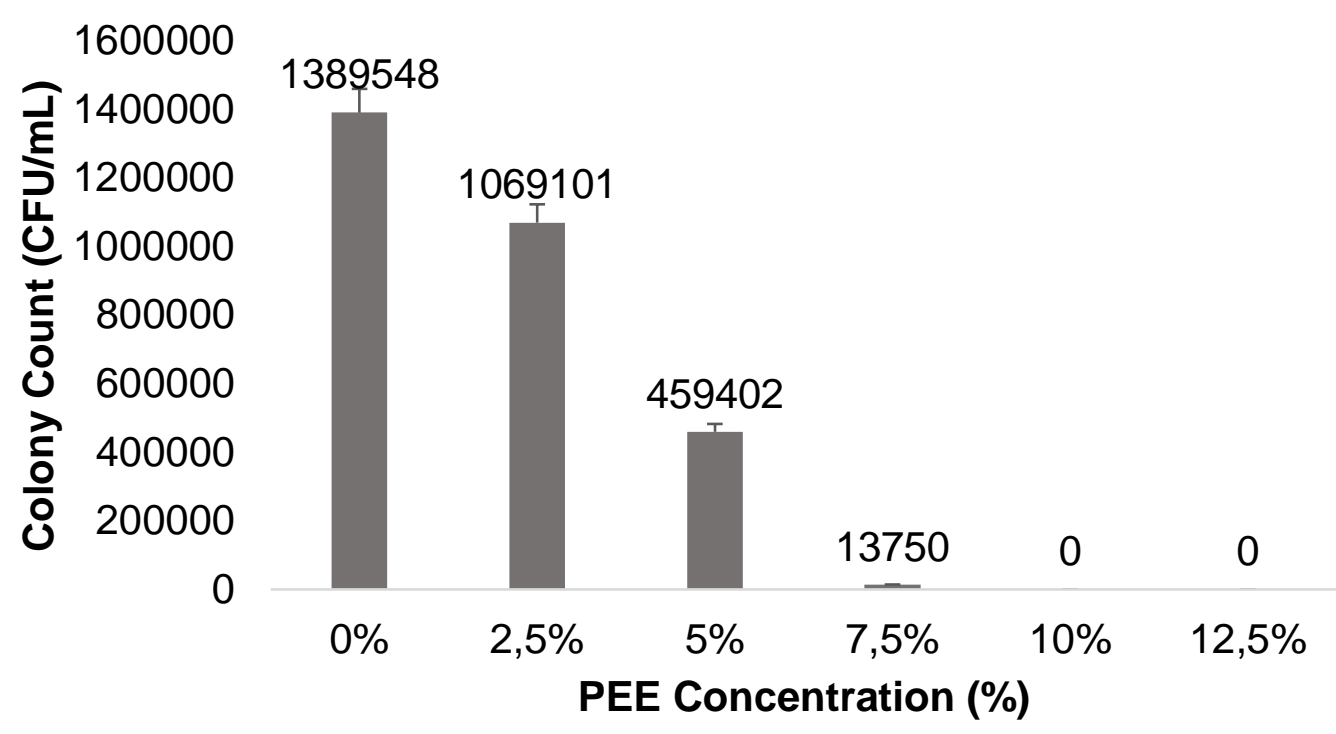

Figure 4. Colony Count Histogram of $C$. albicans Viable Cell on Biofilm Formation with some Concentrations of Propolis Ethanol Extract Treatment (0\%; 2.5\%; 5\%; $7.5 \% ; 10 \% ; 12.5 \%)$. The Histogram Showed that Propolis Ethanol Extract can

Decrease the $C$. albicans Cell Viability on Biofilm Formation. 
Other research revealed the similiar result about PEE effect to cell viability of C. albicans biofilm. The experiment conducted by Capoci et al. (2015) showed that there is a colony decrease with the increase of Brazilian propolis extractive solution (PES) concentration. They find out that cell viability at the highest concentration of PES in their study $(546.87 \mu \mathrm{g} / \mathrm{mL}$ ) was $42.24 \%$ (Capoci et al., 2015). Therefore, our study has revealed that $10 \%$ concentration of PEE can decreased the cell viability until $0 \mathrm{CFU} / \mathrm{mL}(0 \%)$. This can happen because propolis has a various chemical composition according to the geographical origin. Bees gather the resins and plant substances from plants around them, which vary from region to region (Cheng et al., 2013). Propolis used in this study was come from Lawang, Malang, Indonesia, that has a good plant sources, water availability, geographical and climatic condition.

There are several mechanisms of propolis in damaging cells. Propolis is known to damage the cell wall and cytoplasm (Tyagi et al., 2013). Even though, cell wall integrity has an important role in cell division. Then, the flavonoid in propolis can inhibit the oxidative phosphorylation process, consequently, the ATP formation is inhibited. It can cause the lack of energy to grow properly. Therefore, cell viability will decrease (Majiene et al., 2010).

The results obtained in this study show that PEE has antibiofilm effect against C. albicans biofilm formation in vitro. This indicates that PEE is likely to be one of alternatives to recurrent vulvovaginal candidiasis treatment, especially caused by $C$. albicans biofilm formation. But, this study has limitations. The limitation is this research has not been done in vivo. So that this research has not been able to determine the toxic dose of propolis. Moreover, this study did not measure the flavonoid content of propolis from Lawang, Indonesia.

\section{CONCLUSION}

The purpose of this study was to know the effect of propolis ethanol extracts on the cell adhesion index, morphology, and viability of $C$. albicans cells on biofilm formation. The adhesion index significantly decreased at the concentration of $12.5 \%$ PEE. Hyphal growth was optimally inhibited at the concentration of $12.5 \%$ PEE. The viability of $C$. albicans cells on biofilm formation decreased at $2.5 \%$ concentration and was not seen at $10 \%$ concentration of PEE. Therefore, PEE is likely to be one of alternatives to recurrent vulvovaginal candidiasis treatment, especially caused by $C$. albicans biofilm formation. Future study needs to examine the effect of Indonesian PEE from Lawang, Malang to $C$. albicans biofilm in vivo and its toxic dose. Besides that we recommend to measure the flavonoid content of propolis from Lawang, Indonesia.

\section{ACKNOWLEDGEMENT}

The authors would like to thank all parties involved in this study.

\section{CONFLICT OF INTEREST}

The authors declare that there are no conflicts of interest regarding the publication of this paper. 


\section{REFERENCES}

Aboody, M. S. A., \& Mickymaray, S. (2020). Anti-Fungal Efficacy and Mechanisms of Flavonoids. Antibiotics, 9(2), 45.

Anjum, S. I., Ullah, A., Khan, K. A., Attaullah, M., Khan, H., Ali, H., ... \& Adgaba, N. (2019). Composition and functional properties of propolis (bee glue): A review. Saudi Journal of Biological Sciences, 26(7), 1695-1703.

Capoci, I. R. G., Bonfim-Mendonça, P. D. S., Arita, G. S., Pereira, R. R. D. A., Consolaro, M. E. L., Bruschi, M. L., ... \& Svidzinski, T. I. E. (2015). Propolis is an efficient fungicide and inhibitor of biofilm production by vaginal Candida albicans. Evidence-Based Complementary and Alternative Medicine, 2015.

Cavalheiro, M., and Teixeira, M.C., (2016). Candida Biofilms: Threats, Challenges, and Promising Strategies. Front. Med, 5(28), 1-15.

Cheng, H., Qin, Z. H., Guo, X. F., Hu, X. S., \& Wu, J. H. (2013). Geographical origin identification of propolis using GC-MS and electronic nose combined with principal component analysis. Food research international, 51(2), 813-822.

Chua, EG., Parolia, A., Ahlawat, P., Pau, A., Amalraj, D., (2014). Antifungal Effectiveness of Various Intracanal Medicaments Againts Candida albicans: an ex-vivo study. BMC Oral Health; 14(53), 1-8.

De Castro, P. A., Bom, V. L. P., Brown, N. A., de Almeida, R. S. C., Ramalho, L. N. Z., Savoldi, M., ... \& Goldman, G. H. (2013). Identification of the cell targets important for propolis-induced cell death in Candida albicans. Fungal Genetics and Biology, 60, 74-86.

El-Din, A. Z. A. K., Al-Basri, H. M., \& El-Naggar, M. Y. (2012). Critical factors affecting the adherence of Candida albicans to the vaginal epithelium. Journal of Taibah University for Science, 6(1), 10-18.

Gonçalves, B., Ferreira, C., Alves, C. T., Henriques, M., Azeredo, J., and Silva, S., (2016). Vulvovaginal candidiasis: Epidemiology, microbiology and risk factors. Critical Reviews in Microbiology, 42(6), 905-927.

Hadi, Wiyono, Handoko, E., Noorhamdani, and Prawiro, S. R. (2019). Effect of Ethanolic Extract Propolis Trigona spp. Malang Indonesia on Isolate Staphylococcus aureus Biofilm Architecture from Chronic Rhinosinusitis A Confocal Laser Scanning Microscopic Study. Int J Pharm Sci \& Res. 10(6), 2711-17.

Lagrouh, F., Dakka, N., \& Bakri, Y. (2017). The antifungal activity of Moroccan plants and the mechanism of action of secondary metabolites from plants. Journal de mycologie medicale, 27(3), 303-311.

Li, Y., Shan, M., Yan, M., Yao, H., Wang, Y., et al., (2019). Anticandidal Activity of Kalopanaxsaponin A: Effect on Proliferation, Cell Morphology, and Key Virulence Attributes of Candida albicans. Front. Microbiol, 10 (2844), 1-9.

Majiene, D., Macioniene, I., Kursvietiene, L., Bernatoniene, J., Davalgiene, J., Lazauskas, R., \& Savickas, A. (2010). The effect of propolis on microbial vitality and oxygen consumption. Journal of Medicinal Plants Research, 4(10), 954-958.

Mutiawati, V., (2016). Pemeriksaan Mikrobiologi Pada Candida albicans. Jurnal kedokteran syah kuala, 16 (1), 121-128.

Nagayama, K., Oguchi, T., Arita, M., \& Honda, T. (1995). Purification and characterization of a cell-associated hemagglutinin of Vibrio parahaemolyticus. Infection and immunity, 63(5), 1987-1992.

Nani, B. D., Sardi, J. D. C. O., Lazarini, J. G., Silva, D. R., Massariolli, A. P., Cunha, T. M., ... \& Rosalen, P. L. (2019). Anti-inflammatory and anti-Candida effects 
of brazilian organic propolis, a promising source of bioactive molecules and functional food. Journal of Agricultural and Food Chemistry, 68(10), 28612871.

Okińczyc, P., Paluch, E., Franiczek, R., Widelski, J., Wojtanowski, K. K., Mroczek, T., ... \& Sroka, Z. (2020). Antimicrobial activity of Apis mellifera L. and Trigona sp. propolis from Nepal and its phytochemical analysis. Biomedicine \& Pharmacotherapy, 129, 110435.

Richardson, J. P., Ho, J., \& Naglik, J. R. (2018). Candida-epithelial interactions. Journal of fungi, 4(1), 22.

Shehu, A., Ismail, S., Rohin, M. A. K., Harun, A., Aziz, A. A., \& Haque, M. (2016). Antifungal properties of Malaysian Tualang honey and stingless bee propolis against Candida albicans and Cryptococcus neoformans. Journal of Applied Pharmaceutical Science, 6(2), 044-050.

Silva-Carvalho, R., Baltazar, F., \& Almeida-Aguiar, C. (2015). Propolis: a complex natural product with a plethora of biological activities that can be explored for drug development. Evidence-Based Complementary and Alternative Medicine, 2015.

Tsang,P., Bandara,H., Fong,W., (2012). Purpurin Suppresses Candida albicans Biofilm Formation and Hypal Development. PLOS One, 7(11), 866-874.

Tyagi, S. P., Sinha, D. J., Garg, P., Singh, U. P., Mishra, C. C., \& Nagpal, R. (2013). Comparison of antimicrobial efficacy of propolis, Morinda citrifolia, Azadirachta indica (Neem) and $5 \%$ sodium hypochlorite on Candida albicans biofilm formed on tooth substrate: An in-vitro study. Journal of conservative dentistry: $J C D, 16(6), 532$.

Valerio, F. K., Bonfim-Mendonça, P. S., Rosseto, H. C., Bruschi, M. L., Henriques, M., Negri, M., Svidzinski, T. I., (2016). Propolis: a potential natural product to fight Candida species infections. Future Microbiology, 11(8), 1035-1046.

Zhang, H., Li, J., Zhang, J., Shi, H., Lin, X., \& Sun, H. (2016). Purpurin inhibits the adhesion of Candida albicans biofilms. International Journal of Clinical \& Experimental Medicine, 9(6). 